\title{
Fiebre de oro en tiempos de "paz" - dimensiones e implicaciones del avance aurífero en el Cauca (Colombia) después del Acuerdo de la Habana
}

\section{Gold fever in times of "peace" - dimensions and implications of the gold advancement in Cauca (Colombia) after the Havana Peace Agreement (Abstract)}

\author{
Mary Cusi ${ }^{1}$; Dorothea Hamilton ${ }^{2}$; Alison Peralta ${ }^{3}$; Anamaría Ruíz ${ }^{4}$ \\ 1 Universidad Nacional Mayor de San Marcos, Instituto de Geografía (Perú). marycriscp@gmail.com \\ 2 Justus Liebig Universität Gießen, Instituto de Geografía (Alemania). \\ dorothea.hamilton@geogr.uni-giessen.de \\ 3 Cooperacción (Perú). aperalta@cooperaccion.org.pe \\ 4 Universidad Externado de Colombia, Instituto de Geografía (Colombia). \\ anamaria.ruiz@est.uexternado.edu.co
}

\begin{abstract}
RESUMEN
La firma de la paz en Colombia entre las Fuerzas Armadas Revolucionarias de Colombia (FARC) y el gobierno colombiano, logró cesar un conflicto armado muy violento que duró más de 50 años. Tras la firma del acuerdo, realizada en La Habana en noviembre 2016, resultan como retos más urgentes el control del territorio que dejó la desmovilización de las FARC y el manejo de la riqueza de los recursos naturales. El Cauca (suroccidente del país) es uno de los departamentos más afectados por la violencia y puede considerase una de las regiones de mayor conflicto. Las razones son el nivel de desigualdad y la presencia de varios grupos armados en el departamento, sumado a esto la multietnicidad y la riqueza en recursos naturales. Respecto a este último punto, el oro es objeto de debate y conflicto en los últimos años. Tanto la minería a gran escala como la minería artesanal, informal, ilegal y criminal han alimentado el conflicto por su incremento acelerado. $Y$ mientras el gobierno nacional busca promover un desarrollo a través de la inversión internacional, existen distintas percepciones locales en contra. Los objetivos principales de este artículo son investigar cuáles son las dimensiones de la minería aurífera, legal e ilegal, y hacer un balance de las implicaciones, es decir: cuantificar algunos efectos económicos, ecológicos y sociales de la minería ilegal. Entre ellos investigamos la relación espacial entre los asesinatos de defensores de derechos humanos y la presencia de minería en cualquiera de sus dimensiones. Aunque encontramos una relación directa entre la minería ilegal y las violaciones de derechos humanos, podemos comprobar que tanto la minería ilegal como la legal se convierten en un riesgo para la paz.
\end{abstract}

Palabras clave: Minería ilegal; Defensores de derechos humanos; Minería aurífera; Posconflicto; conflicto de recursos naturales.

Cusi, M., Hamilton, D., Peralta, A. \& Ruíz A. (2019). Fiebre de oro en tiempos de "paz" - dimensiones e implicaciones del avance aurífero en el cauca (Colombia) después del Acuerdo de la Habana. Espiral, revista de geografías y ciencias sociales, 1(1), 029 - 044. http://dx.doi.org/10.15381/espiral.v1i1.15844 


\begin{abstract}
The signing of peace agreement in Colombia between the FARC (Revolutionary Armed Forces of Colombia) and the Colombian government, ended the armed conflict that lasted for more than 50 years. After the signing the most urgent challenges are: the control of the territory left by the disbandment of the FARC and the management of the wealth of natural resources in the respective areas. The Cauca department is situated in the country's southwest and has been one of the most affected by the past violence and is considered to be amongst the most complicated regions to implement peace. Reasons being the high level of inequality, the presence of several armed groups, multiethnicity and its wealth in natural resources, especially gold. Gold has become subject of dispute and conflict in recent years. Both large-scale mining and artisanal, informal, illegal and criminal mining have fueled conflict by its accelerated spreading due to the risen goldprice. And, while the national government seeks to promote development through international investment, locals are many times opposed to any kind of mining activities. The Principle objective of the article is to investigate on the dimensions of legal and illegal gold mining in the Cauca after the signing of the peace contract and quantify economical, ecological and social dimensions of illegal mining. Among them we emphasize the spatial relationships between illegal mining and murders of human rights defenders. Although we do not find a direct relationship between illegal mining and human rights violation in all muncipialities, we show that illegal and legal mining is a threat to peace.
\end{abstract}

Keywords: Illegal mining; Human rights defenders; Gold mining; Post conflict; conflict over natural resources.

El Cauca es considerado uno de los lugares con mayores retos para implementar el Acuerdo de paz firmado en La Habana, en noviembre 2016. El Cauca está situado en el suroccidente del país, tiene un vínculo intenso con el corredor hacía Ecuador y una salida al mar; además, es un departamento que cuenta con una gran variedad de pisos bioclimáticos y propiedades minerales de los suelos ígneos, por estar ubicado entre las cordilleras Occidental y Central. Así, tanto por su posición estratégica, por el potencial agrícola que permite una alta densidad de plantaciones ilícitas (coca, amapola, marihuana) y por la minería ilegal, este departamento fue un fuerte escenario de conflicto entre las FARC, otros grupos insurgentes, grupos paramilitares y el ejército nacional (Duarte y Betancourt, 2017). Las FARC tuvieron presencia en 35 de los 44 municipios y controlaron una gran parte de las zonas de economía ilegal (PARES, 2018). Los índices de violencia superaron el doble de los índices nacionales en el auge de la violencia caucana en 2012: la tasa de homicidios alcanzó un promedio de 61,42 por cada 1.000 personas, más que el promedio nacional $(32,33)$. Además, el Cauca cuenta con una alta cifra de desplazamiento interno en todo el país. Para el 2014, la cifra oscilaba entre 248,791 y 249,265 desplazados (RNI, 01 nov 2018).

Después del desarme del principal grupo insurgente, el Cauca se convirtió en uno de los departamentos más peligrosos para los defensores de derechos humanos y ambientales. Con 84 asesinatos, casi la cuarta parte de todos los asesinatos de líderes locales han sido reportados en el Cauca (El Tiempo, 2018), entre enero de 2016 y agosto de 2018. Se pueden mencionar distintas causas que han dado forma al conflicto interno nacional, entre las cuales cabe resaltar las disputas sobre el territorio del departamento, entre grupos armados nuevos y tradicionales, denominados bandas criminales. Un punto relacionado al anterior es el control de economías ilegales, como las plantaciones ilegales de coca y minería ilícita (Duarte y Betancourt, 2017).

Según el Atlas Básico de Colombia, publicado por el Instituto Geográfico "Augustín Codazzi" en 1970, se encuentran altas cantidades de oro en todo el departamento. Sin embargo, estos yacimientos no fueron explorados de manera tecnificada hasta hace aproximadamente 20 años (UNODC, 2016). Con el aumento en los precios de metales preciosos entre 2000 y 2014, hubo una fuerte expansión de la minería ilegal, y solo a partir del año 2012 este tipo de extracción minera, realizada a través de maquinaria pesada y sin ningún tipo de licencia ambiental fue regulada

030 | Espiral 1(1): 030 - 044 
y penalizada como un delito en el país. Sin embargo, esta minería muchas veces está relacionada con el financiamiento de grupos armados, y ha aumentado desde entonces. Según Rettberg \& Ortíz-Riomalo (2016) hay dos tipos de financiamiento de grupos armados a través de la minería ilegal: la vía directa la explotación de los yacimientos por grupos armados o financiamiento indirecto a través de pagos de tasas de seguridad hacia el grupo.

Al mismo tiempo, aumentaron los esfuerzos del gobierno nacional por vender concesiones legales a inversores internacionales para aumentar el ingreso a través de las regalías y para traer desarrollo a zonas rurales periféricas. Hasta el momento solo un $13 \%$ de las 52 toneladas producidas en Colombia provienen de grandes producciones de oro (Riaño, 2017), 45,2 toneladas fueron producidas sin permisos y licencias, incluyendo minería no-maquinizada y realizada con maquinaria pesada y químicos, denominada ilegal. Después de que las FARC dejaron las armas, grandes territorios ricos en oro quedaron en disputa, y tanto la minería ilegal como la minería legal generan distintos conflictos entre las comunidades, las autoridades locales y los futuros inversionistas. En el presente artículo tratamos de cuantificar las dimensiones e implicaciones de la minería aurífera en el Cauca con respecto a la firma del tratado de paz relacionando efectos ecológicos, económicos y sociales.

\section{Metodología}

Para entender los efectos de la extracción de oro en el territorio Caucano fue necesario entender su ubicación espacial y aspectos como la localización de los lugares en donde se realiza minería, tanto legal como ilegal; los lugares donde ocurrieron los asesinatos de defensores de derechos humanos y ambientales; la presencia de las FARC antes del acuerdo y de bandas criminales después del Acuerdo de La Habana. No pretendemos, en este articulo, dar una lista completa de los lugares en los que hay minería ilegal, pero tratamos de acercarnos al tema de manera cuantitativa. Usamos el mínimo denominador común, municipio, como una referencia espacial, a pesar de que estos sean mejor denominados como regiones administrativas. Siendo un tema de ilegalidad con cambios constantes, es imposible utilizar datos completamente actualizados o correctos. Sin embargo, la aproximación más exacta que logramos hacer al tema es a través del análisis de los datos existentes.

En primer lugar, se realizaron entrevistas con funcionarios públicos, intelectuales, activistas, líderes locales y ex miembros de las FARC en diferentes municipios del Cauca acerca de su percepción del tema, con las cuales se lograron una fuente importante de recopilación de datos. Luego se georreferenciaron los datos recopilados acerca de la minería aurífera aluvial, con base en un informe del United Nation Organisation on Drugs and Crime (UNODC, 2016) que permitió entender la ubicación administrativa. Los datos se complementaron con los datos de un informe de la policía regional acerca de las intervenciones policiales en el Cauca entre 2016 y 2018. La obtención de la información acerca de los asesinatos de defensores de derechos humanos se realizó a partir de un informe de la Marcha Patriótica (2018) que incluye todos los miembros asesinados hasta marzo 2018. La información de los municipios donde hay presencia de las FARC y bandas criminales, después del desarme fue citado por la Fundación de Ideas para la Paz (PARES, 2017).

\section{Implicaciones del "desarrollo" a través de la inversión en el sector minero}

La minería, o los proyectos extractivos, son una estrategia nacional para lograr el desarrollo económico a nivel del país; además, constituye la apuesta por la institucionalidad, por una gobernanza democrática para salir de la identidad tercermundista que globalmente se le ha asignado, es decir, una identidad en la que es considerado un país en vía de desarrollo con menos capacidades de aprovechar

Espiral 1(1): 031 - 044 | 031 
los recursos. A su vez, fomenta la jerarquía centralizada sobre las regiones especialmente ricas en recursos naturales. Según esta lógica países como Colombia han atraído la inversión de proyectos extractivos -siendo privilegiados por contar con recursos naturales como el oro- con políticas que favorecen la implementación y ejecución de los proyectos extractivos más grandes, en miras de acrecentar el Producto Interno Bruto (PBI) del país. Sin embargo, hay que relacionar los logros del tan soñado "desarrollo" en la convivencia de poblaciones rurales y originarias con megaproyectos extractivos.

Los proyectos extractivos se ubican casi siempre en zonas rurales donde la población tiene escasa instrucción, vive en su mayoría de la agricultura y muchas veces de la minería artesanal. Y uno de los fenómenos que se presenta y ocasiona conflictos sociales, es que las comunidades, se dividen cuando llegan las grandes mineras y les muestran los beneficios que supuestamente tienen para ellas la consolidación de un gran proyecto minero. Aparecen pues unos grupos en contra del denominado "desarrollo" y otros a favor de este, generándose conflictos sociales con consecuencias mortales (OCMAL 2018).

Es claro que una paz duradera no se puede lograr sin una estabilidad económica, para ello, y según las teorías neoliberales reforzadas a partir del Consenso de Washington, fueron implantadas las siguientes medidas económicas: la liberalización del comercio internacional, privatizaciones y desregulación ambientales, un poder judicial independiente y derechos de propiedad bien protegidos (Coy et al., 2017). Esto resulta en la competitividad entre los países para atraer inversión internacional y ser reconocidos en el mercado global. Sin embargo, debemos señalar que estas teorías hacen hincapié en la prosperidad y el desarrollo económico, presumiendo que el crecimiento económico conlleva de manera infalible al progreso integral de todo el territorio estatal, por tanto, casi equiparando el crecimiento económico al desarrollo, y donde el primero (el crecimiento) es el objetivo fundamental.

Desde la explotación de su riqueza aurífera, Colombia ha apostado por buscar nuevas alianzas con el sector privado, centrándose tradicionalmente en la extracción de hidrocarburos. Por la experiencia de países vecinos se sabe que bien se ha incrementado el PBI, y que la dinámica económica está teniendo grandes consecuencias sociales, ecológicas, políticas y económicas; sobre todo cuando la brecha de la desigualdad se agudiza entre las comunidades, regiones e instancias nacionales.

La riqueza de oro sobre un territorio implica contradicciones: por un lado, puede generar puestos de trabajo para los pobladores rurales; por otro lado, cuando se practica como una gran minería, acarrea distintos conflictos sobre el derecho del oro y del agua. Podemos ver como, gracias al proceso de formalización de la extracción, se han agravado los conflictos sociales generándose mayor desconfianza entre las poblaciones, las empresas y un Estado, que parece estar ausente. En cuanto a la minería ilegal, el mayor ejemplo de la catástrofe social y ambiental es el actual estado del departamento de Madre de Dios.

Entre las problemáticas del avance de la minería a gran escala podemos encontrar el diálogo: el esfuerzo por tener una comunicación entre las empresas, el Estado y las comunidades; no obstante, muchas veces son insuficientes porque en esta relación todavía no se logra un diálogo horizontal, de respeto y confianza. Si bien existen, a través de la consulta previa, métodos de mitigar los conflictos sociales, la apuesta nacional de atraer empresas internacionales para explotar la riqueza aurífera en Colombia conllevará una serie de problemas ambientales y sociales en las áreas afectadas. A su vez, faltan medidas para combatir la minería depredadora y dar posibilidad a la minería de pequeña escala que aporta a las vidas tradicionales de zonas rurales. 


\section{Clasificaciones de minería en Colombia}

Al igual que en Perú, los recursos mineros son propiedad del Estado (Art.5Ley685/01), esto significa que cualquier tipo de explotación minera debe ser regulada por el Estado y que los títulos mineros son otorgados por el mismo; además, toda minería debe ser para la utilidad pública. Según la clasificación legal, los tipos de minería dependen del tamaño o la producción, así se diferencia gran minería, mediana minería, pequeña minería y la minería de subsistencia (MIN. MINAS, 2016). A continuación, advertiremos la clasificación de la minería aurífera en Colombia:

Minería legal, cuenta como cualquier actividad minera que consta de la concesión de exploración y de explotación al igual que las licencias ambientales necesarias y cumple con todas las regulaciones de las relaciones jurídicas entre los particulares y el Estado. Sin embargo, existen una serie de posibilidades de ejercer minería sin ser propietario de una concesión. Fuera de eso existe la minería de subsistencia y dentro de esta el barequeo, que permite sacar minerales sin la utilización de maquinaria pesada. Este método permite sacar $360 \mathrm{~g}$ de oro por año. El barequeo es un tipo de minería tradicional de las comunidades afro del Pacífico colombiano, que en el transcurso de la historia ha sido utilizado por las comunidades rurales, e impulsado primordialmente por las mujeres (Acendra 2017). Consiste en el lavado de arenas, por medios manuales.

Por minería ilegal se entiendo cualquier actividad que se realice fuera del marco legal establecido, incluyendo cualquier actividad subterránea. En las clasificaciones no legales existen además la minería criminal, que se financia directamente de grupos armados ilegales (guerrillas, paramilitares, narcotraficantes) y la minería informal (Guío y Peréz, 2017). Al contrario de la legislación peruana, en Colombia la minería informal no existe de jure, sin embargo, muchos mineros no formalizados entran en esta categoría.

Teniendo en cuenta lo anterior, el Estado ha tenido tres intentos fallidos de legalización de mineros informales. Fallidas porque, para el 2013 el 62 \% de los yacimientos o actividades mineras seguían siendo ilegales, contando con que la mayoría de este porcentaje era de minería a pequeña escala, y que además no se logró tampoco formalizar ninguna pequeña asociación minera (Guiza, 2013). Fuera de los problemas ecológicos que genera la minería informal, se logra evidenciar la falta de control estatal como en la diferenciación de la minería criminal.

\section{Dimensiones del avance de la minería aurífera en el Cauca}

Según el Ministerio Energías y Minas, el Cauca es el quinto productor nacional de oro en Colombia (Ministerio de Minas y Energías, 2016). Según las cifras oficiales, en el 2016 fueron producidas 3.7 toneladas de oro que equivale a un valor aproximado de 144353500 USD. Esta cifra plantea el asunto de pensar quién distribuye los beneficios obtenidos de la riqueza aurífera y cómo lo hace.

Según las clasificaciones anteriores, los ingresos y los tipos de minería se distribuyen de la siguiente manera:

La minería artesanal se sigue elaborando en los ríos de casi todo el territorio Caucano. El ingreso es mínimo y difícil de calcular. Por ser un oficio sin el uso de maquinaria, su impacto, tanto económico como ecológico, es casi imperceptible a nivel regional, aunque representa ingresos fundamentales para la subsistencia de las comunidades rurales que la realizan.

En 2017 existían 225 concesiones mineras que ejercían minería legal. De estas, 45 incluían minería aurífera y se repartían en 20 municipios. Los títulos mineros auríferos incluyen 4680,5 $\mathrm{km}^{2}$ (cerca de $16 \%$ de la superficie del Cauca). Según la 
Agencia Nacional de Minería, la mayoría de los titulares eran personas naturales, pero si se compara el área de la superficie, las empresas internacionales son titulares de la mayor parte de las concesiones. Mientras las comunidades étnicas solo abarcan $2 \%$ de todos los títulos (ver Tabla 1). Aunque por el momento no existe una minería a gran escala en fase de explotación, las concesiones actuales demuestran que es muy probable que, en un futuro, el Cauca abarque una mina a cielo abierto con inversión extranjera en su territorio. Desde el punto de vista de las compañías mineras, la explotación de oro es una vía al desarrollo nacional y regional. La firma de la paz es la precondición para ejecutar las explotaciones con menor riesgo. A la vez, la paz permite las 3 iniciativas que se oponen a la explotación aurífera en su municipio a través de la consulta popular.

Tabla 1. Títulos auríferos en el Cauca (NM, 2017)

\begin{tabular}{lccc}
\hline \multicolumn{1}{c}{ Titulares } & $\mathbf{N}^{\circ}$. de títulos & hectáreas & \% de títulos (hectáreas) $^{\mathbf{1}}$ \\
\hline Comunidades étnicas & 5 & 9480,01 & $2,2 \%$ \\
Pequeñas/medianas empresas & 9 & 107823,11 & $23,0 \%$ \\
Grandes empresas nacionales & 2 & 27584,50 & $5,9 \%$ \\
Empresas internacionales & 9 & 237335,29 & $50,7 \%$ \\
Personas naturales & 12 & 85832,69 & $18,3 \%$ \\
\hline
\end{tabular}

Elaboración propia.

1 Esta unidad de medida, hace alusión al porcentaje en hectáreas, del área perteneciente al departamento del Cuaca, que posee cada titular

Se evidencia minería ilegal o criminal aurífera en 18 de 42 municipios estudiados. Según Heck (2014), 57 minas de mediana escala y 419 de pequeña escala se trabajaron en el Cauca para el 2014. Según el análisis del UNODC, contamos 34 lugares dentro del Cauca donde se ejerce minería ilegal de aluvión (ver Fig. 1). De acuerdo con los cálculos elaborados en este artículo, en $2014109534 \mathrm{~m}^{2}$ (cerca de 10 hectáreas) han sido afectados por la minería de aluvión. La Fig. 2 evidencia las áreas afectadas por la minería ilegal y enseña claramente el aumento drástico de entre 2011 y 2014. Aunque falten datos actuales del avance minero después del acuerdo de paz, las entrevistas demuestran que no ha disminuido la minería ilegal después del desarme de las FARC. De las zonas de minería de aluvión, exceptuando 3, se encontraban todas situadas en municipios que tenían presencia de las FARC antes del entregue de las armas.

La información acerca de la minería de filón que puede denominarse como minería de media y pequeña escala, es más difícil de obtener puesto que muchas veces no se logra demostrar tan claramente en las imágenes satelitales la presencia de este tipo de minería. Sin embargo, utilizamos datos mencionados anteriormente y los recortamos con informaciones de la policía regional acerca de los municipios con intervenciones policiales a la minería ilegal.

Aunque no se debe de criminalizar todo esfuerzo de minería a pequeña escala, mencionamos que hay conexiones entre pequeña minería y minería criminal, dado que la introducción de "oro criminal" al mercado legal tiene que ser a través de otra minería.

\section{Implicaciones del avance aurífero}

Debido a que aún no existe minería a gran escala en el Cauca hasta el momento, nos enfocaremos en algunas implicaciones de la minería informal. Reiteramos que no pretendemos agotar los efectos en su totalidad, pero hacemos un intento por descifrar la minería informal y sus efectos hacia el Cauca, en una fase de transición. 


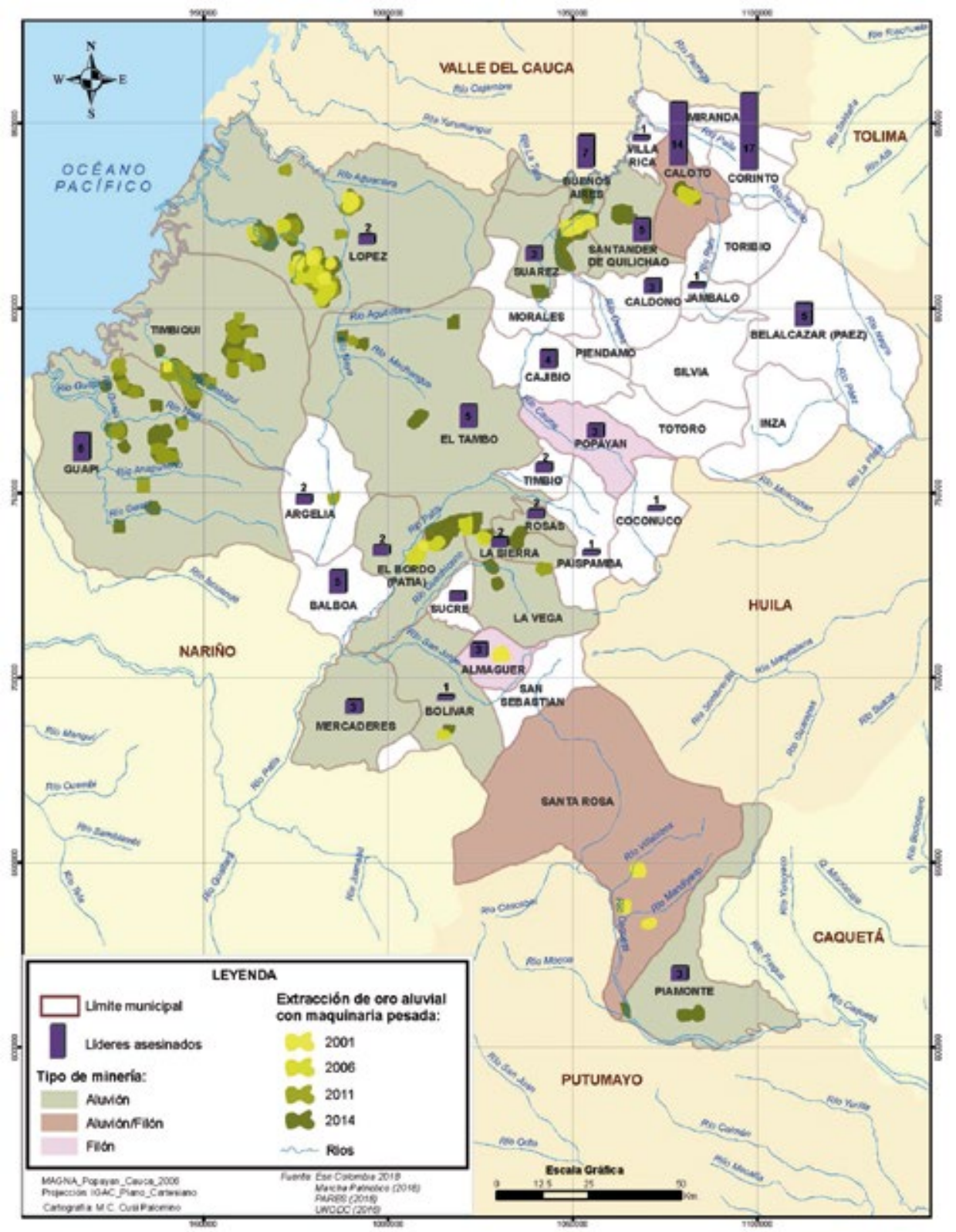

Figura 1. Mapa de la minería aluvial, defensores de D.D.H.H. asesinados, intervenciones policiales, minería y presencia de bandas criminales en los municipios del Cauca.

Fuente: Recopilación de datos según UNODC 2016, Marcha Patriótica, 2018; Policía Nacional del Cauca, 2017; PARES, 2017).

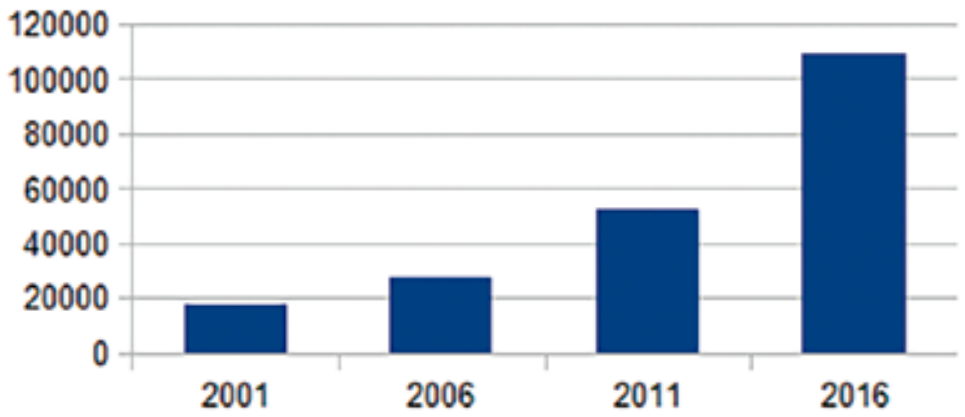

Figura 2. Área afectada por minería aurifera (m2) en el Cauca entre 2001 y 2016.

Fuente: UNODC, 2016.

Espiral 1(1): 035 - $044 \mid 035$ 


\section{Implicaciones sociales: Asesinatos de defensores de D.D.H.H.}

Aunque existen una serie de implicaciones sociales en zonas mineras (Hamilton, 2018), aquí nos enfocamos en las relaciones de minería ilegal con las violaciones de derechos humanos. Una de las hipótesis principales aquí planteadas supone que hay una relación espacial entre minería ilegal y asesinatos de defensores de D.D.H.H. y ambientales. Las razones que la argumentan son la presencia de grupos armados en zonas de minería ilegal, la ausencia del Estado en aquellas zonas y las amenazas reportadas a líderes locales en zonas de minería ilegal desde 2013 (CIMA, 2013). Asimismo, se reportaron amenazas a líderes locales por su actividad en contra de la minería (entrevista a activista).

Según los datos, el Cauca es el lugar de mayor riesgo para los defensores de derechos humanos y ambientales - en 27 de 42 municipios ocurrieron asesinatos en los últimos dos años. En 16 de los municipios coinciden asesinatos y minería ilegal, y en 9 de 41 casos no ocurrieron asesinatos concordando con lugares en donde no hubo minería ilegal (Tabla 2, 3). Eso implica que el riesgo de asesinatos es más alto cuándo hay minería ilegal, aunque es preciso decir que la existencia de minería ilegal no explica en su totalidad los asesinatos.

Tabla 2. Interrelación entre minería ilegal y asesinatos de defensores de derechos humanos.

\begin{tabular}{lcc}
\hline & asesesinatos & sin asesinatos \\
\hline Minería ilegal de filón & $3(7,3 \%)$ & $0(0 \%)$ \\
Minería ilegal de aluvión & $13(31,7 \%)$ & $3(7,3 \%)$ \\
Sin minería ilegal & $13(31,7 \%)$ & $9(21,9 \%)$ \\
\hline
\end{tabular}

Fuente: cálculos basados en información del UNODC, 2016; Policía Regional del Cauca; Marcha Patriótica, 2018.

Tabla 3. Asesinatos, $\mathrm{m} 2$ afectados por la minería aluvial, tipo de minería ilegal y la presencia de bandas criminales.

\begin{tabular}{|c|c|c|c|c|}
\hline Municipio & $\mathrm{m}^{2} \mathrm{~min}$. aluvial & No. de asesinatos & tipo de minería & presencia bacrim ${ }^{2}$ \\
\hline Almaguer & & 3 & filón & \\
\hline Argelia & & 2 & & \\
\hline Balboa & & 5 & & \\
\hline Bolívar & 819,318 & 1 & aluvión & \\
\hline Buenos Aires & 11395,324 & 7 & aluvión & \\
\hline Cajibío & & 4 & & \\
\hline Caldono & & 3 & & \\
\hline Caloto & 3184,124 & 12 & aluvión & sí \\
\hline Corinto & & 17 & & sí \\
\hline El tambo & 16570,902 & 5 & aluvión & \\
\hline \multicolumn{5}{|l|}{ Florencia } \\
\hline Guachené & & 2 & filón & \\
\hline Guapí & 27817,338 & 6 & aluvión & \\
\hline \multicolumn{5}{|l|}{ Inzá } \\
\hline Jambaló & & 1 & & \\
\hline La Sierra & 1326,147 & 2 & aluvión & \\
\hline La Vega & 1052,112 & & aluvión & \\
\hline López de Micay & 25859,301 & 2 & aluvión & \\
\hline Mercaderes & & 3 & aluvión & \\
\hline Miranda & & & & sí \\
\hline \multicolumn{5}{|l|}{ Morales } \\
\hline Páez & & 5 & & \\
\hline
\end{tabular}

036 | Espiral 1(1): 036 - 044 


\begin{tabular}{|c|c|c|c|c|}
\hline Municipio & $\mathrm{m}^{2} \mathrm{~min}$. aluvial & No. de asesinatos & tipo de minería & presencia bacrim $^{2}$ \\
\hline Patía & & 2 & aluvión & \\
\hline Piamonte & 2601,067 & 3 & aluvión & \\
\hline \multicolumn{5}{|l|}{ Piendamó } \\
\hline Popayán & & 3 & filón & \\
\hline \multicolumn{5}{|l|}{ Puerto Tejada } \\
\hline Puracé & & 1 & & \\
\hline Rosas & 2274,918 & 2 & aluvión & \\
\hline \multicolumn{5}{|l|}{ San Sebastián } \\
\hline Santa Rosa & 930,088 & & aluvión/filón & \\
\hline Santander de Quilichao & 3100,918 & 5 & aluvión & sí \\
\hline \multicolumn{5}{|l|}{ Silvia } \\
\hline Sotará & & 1 & & \\
\hline Suárez & 1665,229 & 3 & aluvión & \\
\hline Sucre & & 2 & & \\
\hline Timbío & & 2 & & \\
\hline Timbiquí & 10937,774 & & aluvión & \\
\hline \multicolumn{5}{|l|}{ Toribío } \\
\hline Villa rica & & 1 & & \\
\hline
\end{tabular}

Fuente: Cálculos basados en información del UNODC, 2016; Policía Regional del Cauca; Marcha Patriótica, 2018; PARES, 2017).

2 bacrim: hace referencia a bandas criminales, disidentes del paramilitarismo.

Sin embargo, la relación nos permite diferenciar espacialmente la ocurrencia de los asesinatos con respecto a la minería ilegal. Podemos clasificar cinco grupos de municipios según la cantidad de minería ilegal y el total de asesinatos. Aunque vemos que el tamaño de los conjuntos de yacimientos en minería ilegal no está directamente relacionado con el número de asesinatos de líderes sociales o defensores de D.D.H.H., el análisis nos permite conformar los siguientes grupos de municipios: Grupo 1: Municipios con presencia de minería ilegal, sin asesinatos. Grupo 2: Asesinatos no relacionados con minería ilegal. Grupo 3: Índice alto en minería ilegal y asesinatos. Grupo 4: Índice medio en minería ilegal y asesinatos. Grupo 5: Sin minería ilegal y sin asesinatos. (ver Fig. 3 y 4 ).

Las convenciones del mapa se entienden y deben analizarse de la siguiente forma:

- Bajo control estatal del territorio: Alta actividad en minería y mayor número de asesinatos (rojo): Aquellos municipios con presencia de grandes áreas afectadas por minería ilegal y una tasa alta de asesinatos están marcados de color rojo. Buenos Aires, El Tambo, Guapi, López de Micay califican para este grupo. Es decir, las zonas del Pacífico que antes de la firma del acuerdo estaban parcialmente controladas por las FARC y que tienen presencia de actividad minera desde hace más de 10 años.

- Mediano control estatal del territorio: índices medios de asesinatos y presencia de minería ilegal (rosado): El siguiente grupo se conforma por los municipios donde se detectó minería de aluvión o filón, en menor magnitud, y se registró menor número de asesinatos de defensores de derechos humanos. En este grupo se encuentran los municipios de Bolívar, Caloto, La Sierra, Piamonte, Rosas, Santander de Quilichao, Patía, Mercaderes y Suárez, al igual que los municipios con minería aurífera de filón: Popayán, Almaguer y Guachené. Es un grupo con presencia de grupos étnicos y localizaciones territoriales diversas $y$, por consiguiente, alta heterogeneidad en su economía. Sin embargo, se encuentran en su mayoría en la zona céntrica del Cauca. 
- Índice alto en asesinatos, sin minería ilegal (naranja): Municipios donde los asesinatos están atribuidos a otras condiciones fuera de la minería ilegal, entre ellos Almaguer, Argelia, Balboa, Cajibío, Caldono, Corinto, Guachené, Jambaló, Puracé, Páez, Paletara, Sotará, Sucre, Timbío y Villa Rica. Estos municipios tienen en común la presencia, en su mayoría, de cultivos ilícitos (UNODC, 2016). En el sur se trata de plantaciones de coca, mientras que en las zonas del noroeste son asociados con las plantaciones de marihuana y amapola. En la zona del noroeste se encuentran, además, los grupos étnicos Nasa, Coconuco y Afro, que además tienen conflictos territoriales entre ellos por la delimitación del territorio y el uso del suelo.

- Minería ilegal sin asesinatos (amarillo): Zonas de minería donde aún no ocurren asesinatos, se identifican las siguientes zonas: Timbiquí, Santa Rosa y la Vega. Según el presente estudio, en estos municipios los defensores de derechos humanos y ambientales se encuentran en alto riesgo.

- Zonas libres de minería aurífera ilegal y sin asesinatos de defensores (verde): Los municipios más seguros, donde no registramos ni minería ilegal ni asesinatos son los siguientes: Florencia, Inzá, Miranda, Morales, Piendamó, Puerto Tejada, San Sebanstían, Silvia y Toribío. Queda pendiente hacer un análisis para definir el dominador común de estas zonas.

- El indicador asesinatos de D.D.H.H. y ambientales nos permite entender su relación con la minería ilegal en su contexto geográfico. Hay que diferenciar distintas zonas y distintos efectos del oro sobre el territorio después de la firma de la paz. Queda por observar el desarrollo de minería ilegal en el contexto del aumento de minería legal.

\section{Implicaciones ecológicas}

La minería aurífera no se puede realizar sin altos impactos medio ambientales, debido a las substancias químicas y la alta cantidad de agua necesitada para llevar a cabo los procesos. Así, el impacto que tienen las actividades auríferas sobre el agua y la tierra son inmensos. En este paper, se hace un intento por cuantificar el impacto según interpolaciones. Es importante decir que este análisis se basa en una serie de supuestos, que pueden tener información inexacta. La concentración de oro en las tierras Caucanas es de 1 a 5 gramos por tonelada de tierra. Para sacar el oro de aluvión se requiere $7 \mathrm{~kg}$ de mercurio por cada kilo de oro y hasta 1.000 litros de agua.

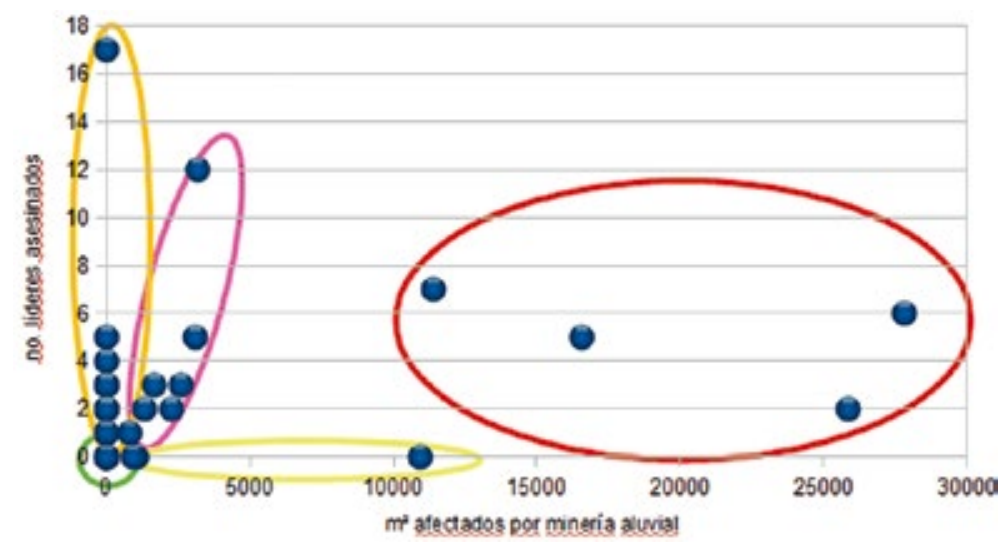

Figura 3. Ocurrencia de asesinatos (número total) y superficie de minería ilegal de aluvión (m2).

Fuente: Cálculos según datos de UNODC, 2016; Marcha Patriotica, 2018). Elaboración propia. 


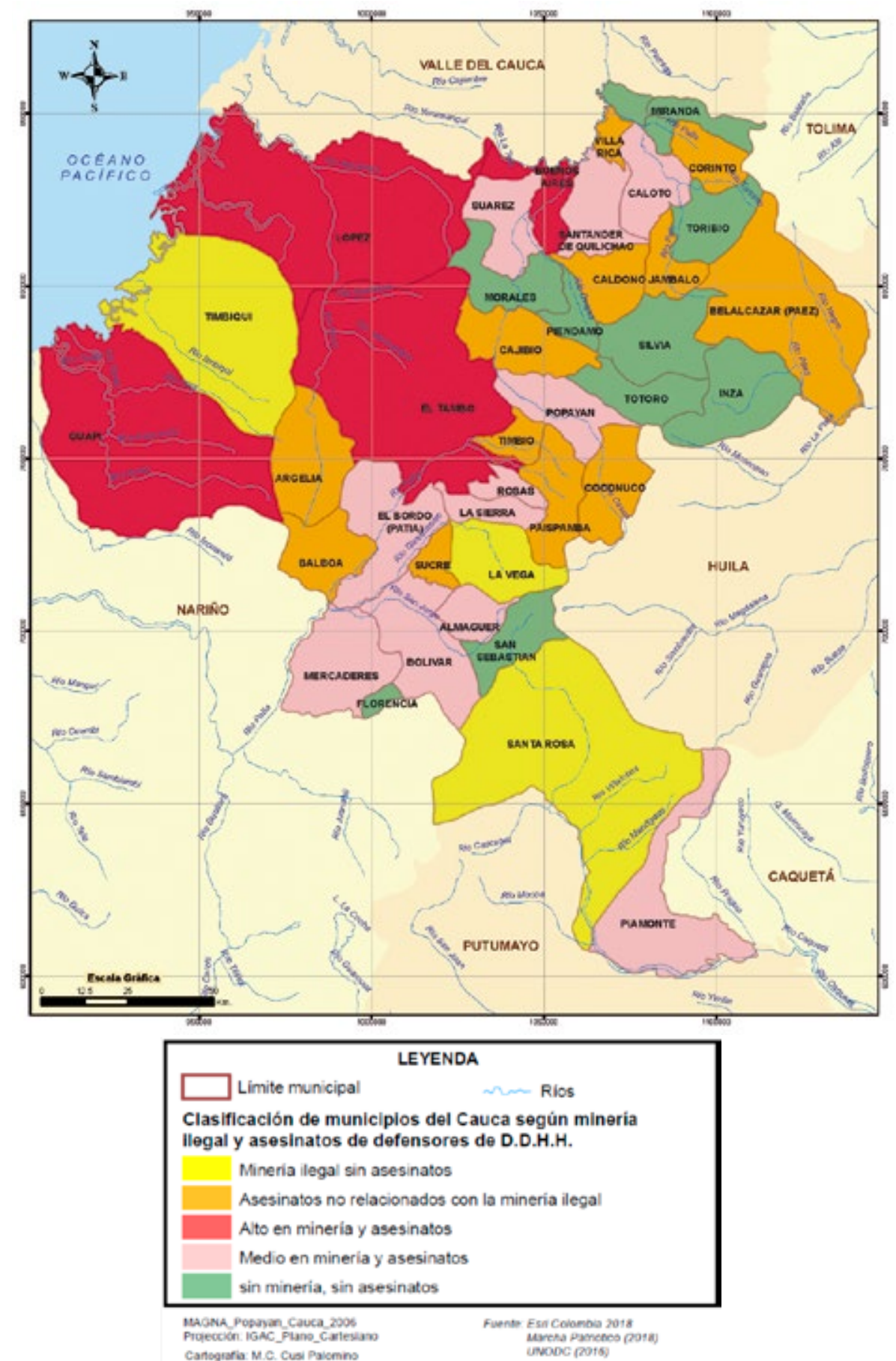

Figura 4. Clasificación de municipios del Cauca según minería ilegal y asesinatos de defensores de D.D.H.H. y ambientales.

El único método para sacar oro de manera sustentable es de la forma tradicional, el barequeo, ya que no supone la misma cantidad de daño para el medio ambiente. Por otro lado la minería de aluvión saca el oro del río con dragas, los efectos que esto conlleva son la destrucción de la vía del río, además de la contaminación del agua por el uso de mercurio o cianuro.

Para cuantificar el impacto en el Cauca, calculamos las toneladas de tierra removida para extraer el oro del río. Según los datos que se lograron extrapolar de entrevistas e información del servicio geológico de Colombia, podría suponerse que, si el $60 \%$ del oro producido en el Cauca proviene de minería ilegal de aluvión, lo que según la UNODC sucede en el resto de Colombia, 2.2 toneladas de oro del Cauca han sido sacadas por dragas. Para sacar tal cantidad, habrían tenido que ser utilizados un total 
de $15.718 \mathrm{~kg}$ de mercurio y removido 4.490 .868 .000 toneladas de tierra. Esta inmensa cantidad de tierra removida ha tenido grandes efectos en casi todas las cuencas.

El impacto de minería legal en el Cauca es aún más difícil de calcular ya que la minería de gran escala trata de promover la "minería bien hecha" (Ministerio de Energías y Minas, 2018). Es decir, un tipo de minería que tenga todas las reglamentaciones ambientales al día, sea "sustentable" y amigable con el medio ambiente, pero técnicamente no se puede ejercer minería aurífera sin alteraciones ambientales o posibles accidentes. Además, el uso de cianuro y los desechos que deja la producción minera tienen efectos a largo plazo sobre el medio ambiente, que son más difíciles de percibir y controlar. Por último, es pertinente resaltar que en el Cauca aún no existe minería a cielo abierto legal, así que es el impacto de la minería subterránea el que tiene, sobre todo, efectos para aguas corrientes.

\section{Implicaciones económicas}

Debido a que se trata de una actividad ilegal, los ingresos económicos de la minería aurífera en el Cauca solo pueden ser extrapolaciones. Rettberg y Ortiz Riomalo (2016) asumen que a nivel nacional el ingreso económico de la minería ilegal por grupos armados es cerca de 10 mil USD al año. Massé (2016) por el contrario calcula el ingreso para grupos armado a 18 mil USD al año.

Según el Ministerio Energías y Minas, en 2016 fueron producidos 3,742 toneladas de oro en el Cauca, lo que equivale un valor de 144,3 mil USD. Según el documento, no hay información acerca de la providencia de fuentes ilegales. Tras la producción de oro legal, existen cadenas ilegales que convierten el oro ilegal en oro legal. Esto puede incluso traspasar límites departamentales o internacionales. En el Cauca, por ejemplo, entrevistas con ex funcionarios de las FARC revelaron la exportación de oro hacia Panamá y Perú, y distintos periódicos nacionales descubrieron el vínculo entre el oro ilegal producido en el Cauca y en Nariño y estructuras mafiosas situadas en Cali (Semana 24.1.2018).

La providencia del oro en el Cauca tiene distintos efectos en la estructura económica local y departamental. Por un lado, la minería ilegal e informal es fuente de trabajo para una gran cantidad de mano de obra no calificada, y por otro lado refinancia nuevos grupos armados que terminan controlando zonas de minería informal e ilegal. Hay muestras del vínculo entre la minería ilegal y el narcotráfico; como el oro puede ser introducido al mercado legal, el ingreso del narcotráfico se revierte en maquinaria para la explotación del oro aluvial (Massé, 2016; Entrevista con el Excomandante de las FARC).

Tal como se explica en algunas de las entrevistas realizadas, una retroexcavadora puede extraer hasta 70 gramos de oro diariamente, esto genera un valor total de oro en 17.000 USD por semana. Según datos de la policía, 178 retroexcavadoras han sido destruidas por el cuerpo policial entre 2014 y 2017 (Policía del Cauca, 2017). Contando con la actividad de aquella maquinaria, se habrían explotado $4.547 \mathrm{~kg}$. de oro por año, llegando a un rédito de 150.000 USD. Las fallas de los números oficiales y las extrapolaciones demuestran, por una parte, las fallas de la explotación, y por otra parte las vías inexactas de medición del oro exportado.

Ahora bien, si se paga el $10 \%$ a un grupo ilegal, como era el caso para las FARC, según cuenta un exguerrillero, se estarían generado 1.5 mil USD al año para nuevos grupos armados. Estos datos dejan claro que la financiación de nuevos grupos armados, por la redistribución de zonas de dichos grupos, permite que se armen, resultando en más terror en estas zonas que se encuentran fuera del alcance gubernamental.

Sin embargo, el impacto económico de la minería aurífera no afecta solamente a los grupos armados, también es una fuente de ingresos para personas que habitan las

040 | Espiral 1(1): 040 - 044 
zonas rurales con poco nivel de estudios formales. Esto mismo genera un aumento de desigualdad entre las comunidades (Hamilton, 2018). Hay que tener en cuenta que, en el Cauca, al contrario de otras zonas colombianas, hay poca tradición de minería tecnificada. Es decir que el aumento drástico de la minería aluvial está manejado por personas ajenas del departamento, como dicen los pobladores. Tanto los operadores de las minas ilegales como los trabajadores son, en su mayoría, mineros migrantes provenientes de otros departamentos.

\section{Conclusiones}

Después del desarme de las FARC, grandes territorios ricos en oro están en disputa y generan nuevos conflictos. Aparte del control territorial, quedan en disputa diferentes formas de desarrollo. El gobierno nacional promueve un desarrollo a través de la inversión internacional; es decir, minería a gran escala. Muchas comunidades se oponen a cualquier tipo de minería y los beneficiarios de la minería ilegal perpetúan el estado de informalidad. La legalización de la minería informal de pequeña escala es tan lenta y burocrática que casi no beneficia a las comunidades locales.

Sin duda, en zonas como el Cauca que han sido el escenario de conflicto entre varios grupos armados, el Estado y diversos grupos étnicos, la riqueza de oro es protagonista. Como fuente de financiamiento de grupos armados, su uso tradicional como minería de subsistencia y, a su vez como posible explotación por mineras internacionales, juega un rol importante para el futuro del departamento.

Por un lado, la minería ilegal coincide con los asesinatos de defensores de D.D.H.H. y ambientales; por otro lado, tiene efectos significantes sobre la ecología y el refinanciamiento de nuevos grupos armados. En este escenario está entrando la minería a gran escala, aprovechándose de la recuperación oficial de las tierras. Sin embargo, hay una nueva emancipación de los pueblos en contra del avance aurífero a través de la consulta popular. Queda por observar la relación entre los pueblos, los mineros informales, y los titulares en el futuro. El estudio deja claro que hay que enfocar el tema del oro en un tiempo de transición hacia un país en paz.

Y, por último, observamos un apoyo institucional hacia la minería a gran escala, mientras que las áreas destinadas a la explotación de minería por comunidades étnicas son diminutas. Las interrelaciones entre minería informal, ilegal, criminal y artesanal, y también muchas veces con autoridades locales, complejizan el tema de la legalización de la minería. Hablando con los pobladores de las zonas auríferas que han convivido toda su vida con grupos armados, el oro y tanto su explotación ilegal como legal, para ellos representa un problema antes que una solución.

\section{Bibliografía}

Acendra, D. (2017) Análisis socio jurídico del barequeo con enfoque étnico-territorial. Caso Suárez Cauca. Maestría thesis, Universidad Nacional de Colombia - Sede Bogotá.

ANM (2017): Caracterización de la actividad minera departamental - Departamento del Cauca. Agencia Nacional de Minería

Bolaños, E. (2015): Magnates del oro versus pequeños mineros. In: El Espectador, 22.11.2015. Online: $\quad$ https://www.elespectador.com/noticias/nacional/flor-se-salio-del-libretoarticulo-600654.

Bustelo, P. (2003): Desarrollo económico: Del concenso de Washington al Post-Consenso de Washignton y más allá. Editorial Complutense, Madrid.

CIMA (2013): La avalancha minera en el Macizo Alto Patía- Una investigación sobre la situación minera en el Macizo Alto Patía. Equipo de Investigación Minero de Comité de Integración del Macizo Colombiano (CIMA). 
Coy, M.; Ruiz Peyré, F. Obermayr, C. (2017): South American resourcescapes: geographical perspectives and conceptual challenges. In: Die Erde 148 (2-3), S. 93-110.

Diaz Salazar, R. (2011): Desigualdades internacionales ¡Justicia ya! Hacia un programa mundial de justicia global. Icaria Editorial.

Duarte, C. \& D. Bentancourt (2017): Los territorios que dejaron las FARC: ¿cómo se vive bajo una paz incompleta? In: Razón publica, 21.08.2017. Online: https://www.razonpublica. com/index.php/conflicto-drogas-y-paz-temas-30/10482-los-territorios-que-dejaron-lasfarc-c\%C3\%B3mo-se-vive-bajo-una-paz-incompleta.html\#.WZzjvBZ7los.facebook.

El Tiempo (30.7.2018): El mapa de la vergüenza. https://www.eltiempo.com/colombia/otrasciudades/el-mapa-de-los-lideres-sociales-asesinados-en-colombia-184408

Guío, S.; Pérez, H., Óscar, I. (2017): Radiografía de los conflictos sociales del sector mineroenergético en Colombia 2000-2016. In: León Valencia und Alexander Riaño (Hg.): La minería en el Posconflicto. Un asunto de quilates. 1a edición. Bogotá D.C. (Colombia): B, Grupo Zeta, S. 93-172.

Güiza, L. (2013): La pequeña minería en Colombia, una actividad no tan pequeña. DYNA. Portal de revistas. Vol. 80 No. 181 pp 109 117. Tomado de: https://revistas.unal.edu.co/ index.php/dyna/article/view/35819

Hamilton, D. (2018): Un "medigo sentado en un banco de oro"? Risiken und Nebenwirkungen des Goldabbaus in Lateinamerika. In: matices (92). S-10-11.

Heck, C. (2014): La realidad de la minería ilegal en países amazónicos. Bolivia - Brasil Colombia - Ecuador - Perú - Venezuela. Lima Perú: Sociedad Peruana de Derecho Ambiental (SPDA).

Instituto Gográfico "Augustín Codazzi" (1970): Atlás Básico de Colombia. Bogotá (Colombia).

Luque Revuelto, R. (2016): Los desplazamientos humanos forzados recientes en el Cauca (Colombia). Características e impactos sociales y espaciales. In: INGEO (65). DOI: 10.14198/ INGEO2016.65.11.

Marcha Patriotica (2018): Abusos de poder contra defensores y defensoras de los derechos humanos, del territorio y del ambiente. Informe sobre Extractivismo y Derechos en la región Andina. Asociación Pro Derechos Humanos (Aprodeh) Broederlijk Delen Colectivo de Abogados José Álvaro Restrepo (Cajar) Centro de Documentación e Información Bolivia (Cedib) Comisión Ecuménica de Derechos Humanos (Cedhu). Bogotá, La Paz, Quito, Brüssel. Online: http://www.broederlijkdelen.be/sites/default/files/downloads/ andesrapport_2018_lr.pdf.

Massé, F. (2016): Minería y post-conflicto: es posibe una minería de oro libre de conflicto en Colombia? In: Juan Carlos Henao and Ana Carolina Gónzalez Espinoza (Hg.): Minería y desarrollo. Minería y comunidades: impactos, conflictos y participación ciudadana. Bogotá (3), S. 257-282.

Ministerio de Minas y Energías (2018): Minería Bien Hecha. Online: https://www.minminas. gov.co/estructura-institucional-minera.

Ministerio de Minas y Energías (2016): ANEXO-MEMORIAS_Mineria. Online: https:// www.minminas.gov.co/documents/10180/23907914/ANEXO-MEMORIAS_Mineria. pdf/0d96bc03-36a4-482e-92aa-ed5444a366c3

OCMAL (2018): Observatorio de Conflictos mineros en América Latina. Online: https://www. ocmal.org/.

PARES (2018): Municipios donde hoy está el ELN y antes estaban las FARC. Fundación Paz y Reconciliación (Bogotá). Online: http://www.pares.com.co/paz-y-posconflicto/ municipios-donde-esta-el-eln-que-antes-de-las-farc/.

Policía Regional de Cauca (2017): Minería ilegal. Asamblea Regional de Cauca. Popayán, Colombia, 03.11.2017.

Rettberg, A. \& J.F. Ortiz Riomalo (2016): Golden Opportunity, or a New Twist on the Resource-Conflict Relationship: Links Between the Drug Trade and Illegal Gold Mining in Colombia. In: World Development 84, S. 82-96.

042 | Espiral 1(1): 042 - 044 
RNI (01, nov. 2018) Victimas del conflicto armado - Desplazamiento [Base de datos] Recuperado de: https://www.scribbr.es/normas-apa/ejemplos-de-las-normas-apa/ejemplo-del-estiloapa-base-de-datos-estadistica/

Semana (2018): Violento comienzo de año en Cauca. In: Semana, 24.01.2018. Online: http:// www.semana.com/nacion/articulo/violento-comienzo-de-ano-en-cauca/554663.

UNODC (2016): Colombia: Explotación de oro de aluvión. Evidencias a partir de percepción remoto. Bogotá.

Valencia, L.; Riaño, A. (Hg.) (2017): La minería en el Posconflicto. Un asunto de quilates. 1 ra edition. Bogotá D.C. (Colombia): B, Grupo Zeta.

Entrevistas citadas:

11.11.2017, Popayán (Cauca), Activista social

8.12.2017, Los Robles (Cauca), Ex-Comandante de las FARC 
044 | Espiral 1(1): 044 - 044 